\title{
Shy-Drager syndrome. Effect of fludrocortisone and L-threo-3,4-dihydroxyphenylserine on the blood pressure and regional cerebral blood flow
}

\author{
S Matsubara, Y Sawa, H Yokoji, M Takamori
}

\begin{abstract}
In nine cases of Shy-Drager syndrome, the changes in blood pressure and cerebral blood flow on sitting up from a supine position were studied. The influence of fludrocortisone, a synthetic mineralocorticoid, and L-threo-3,4dihydroxyphenylserine (DOPS), a precursor of norepinephrine, on these changes was examined. On sitting up, the regional cerebral blood flow (rCBF) measured by $\mathrm{Xe}^{133}$ inhalation showed a tendency to decrease. Fludrocortisone reduced the fall of the mean blood pressure significantly. DOPS reduced the fall of both the diastolic blood pressure and rCBF significantly.
\end{abstract}

Syncope is a disabling symptom of central neurogenic orthostatic hypotension, known as the Shy-Drager syndrome, ${ }^{1}$ but the mechanism of the syncope has not been understood fully. Fludrocortisone, a mineralocorticoid, and L-threo-3,4-dihydroxyphenylserine (DOPS), ${ }^{34}$ an immediate precursor of norepinephrine, are reported to be effective in treating orthostatic hypotension. The effect of DOPS was described in a group of patients with familial amyloid polyneuropathy ${ }^{3}$ and in only one patient with the Shy-Drager syndrome. ${ }^{4}$

To clarify the pathophysiology of the ShyDrager syndrome and evaluate the effect of fludrocortisone and DOPS, we studied changes of mean arterial blood pressure and regional cerebral blood flow ( $\mathrm{rCBF}$ ) in the supine and sitting positions before and after the administration of the drugs in the ShyDrager syndrome.

\footnotetext{
Department of Neurology, Kanazawa University School of Medicine, Kanazawa, Japan S Matsubara Y Sawa H Yokoji M Takamori Correspondence to: Dr Matsubara, Department of Neurology, Kanazawa University School of Medicine, Takaramachi, Kanazawa City, 920 Japan. Received 15 September 1987 and in final revised form and in final revised Accepted 14 March 1990
}

\begin{abstract}
Methods
Cases

This series of cases of Shy-Drager syndrome consisted of seven males and two females aged from 45 to 70 years (average age 57 years). The duration of the illness ranged from one to seven years. All nine patients had orthostatic hypotension, dysuria and ataxia; eight had rigidity of the limbs; seven showed pyramidal signs. Patients were diagnosed as having orthostatic hypotension if their systolic blood pressure fell by more than $20 \mathrm{~mm} \mathrm{Hg}$ when they stood from a supine position. Written consent was obtained from the patients before the investigation.
\end{abstract}

The rCBF was measured by the $\mathrm{Xe}^{133}$ inhalation system (Meditronic Novo Diagnostic Systems, Inhalation Cerebrograph, Denmark) using 32 scintillation detectors placed in parallel. One set of assessments consisted of two measurements, one in the supine and another in the sitting position. The patients were kept in the position for more than 20 minutes before the measurements were taken. Before the second measurement, the residual isotope was studied for five minutes and was taken into account as a background. Of 32 detectors, four near the perimeter of the head occasionally caused problems of fit and we excluded all the data from them in our analyses. The initial slope index ${ }^{5}$ was calculated using the Fourier analysis. ${ }^{6}$ The same set of examinations was carried out on eight normal males and one female aged from 30 to 72 years, average age 52 years. They were found to have no abnormality on physical and neurological examinations, including the measurement of the blood pressure both at supine and standing positions.

After the initial set of measurements, seven patients were treated with fludrocortisone for two weeks. The fludrocortisone was administered in the morning orally at a daily dose of $0.2 \mathrm{mg}$ in five patients, and $0.1 \mathrm{mg}$ in two patients who showed an elevated diastolic blood pressure to above $90 \mathrm{~mm} \mathrm{Hg}$ in the supine position at a daily dose of $0.2 \mathrm{mg}$. Seven patients were treated with DOPS administered orally. It was started at $100 \mathrm{mg}$ in the morning and then increased over two weeks to $200 \mathrm{mg}$ three times a day. After the treatment with each drug the same set of rCBF measurements were carried out at $3 \mathrm{pm}$ as before the treatment. Of nine patients with Shy-Drager syndrome, six had both fludrocortisone and DOPS with an interval of 10 to 14 days in between, one patient each had one of these two drugs, and the remaining patient who had no complaint related to the orthostatic hypotension took neither.

For the statistical analyses, both parametric ( $t$ test and paired $t$ test) and non-parametric (Wilcoxon rank sum test and others) methods were used. Two-tailed analyses were carried out and the difference was estimated to be significant when the $p$ value was less than 0.05 .

\section{Results}

In the supine position, the average mean arterial blood pressure was higher and average rCBF lower in the cases of the Shy-Drager syndrome than in normal controls, but neither 
Table 1 Blood pressure and regional cerebral blood flow at supine and sitting positions

\begin{tabular}{|c|c|c|c|c|c|c|c|c|c|c|c|c|}
\hline \multirow[b]{2}{*}{ Subjects } & \multirow[b]{2}{*}{ (Number). } & \multirow[b]{2}{*}{ Positions } & \multicolumn{2}{|c|}{ Systolic BP } & \multicolumn{2}{|c|}{ Diastolic BP } & \multicolumn{2}{|c|}{ Mean BP } & \multicolumn{2}{|c|}{$r C B F(I S I)$} & \multicolumn{2}{|c|}{ Mean $B P / r C B F$} \\
\hline & & & mean & $(S D)$ & mean & $(S D)$ & mean & $(S D)$ & mean & $(S D)$ & mean & $(S D)$ \\
\hline $\begin{array}{l}\text { Normal controls } \\
\text { Patients }\end{array}$ & (9) & $\begin{array}{l}\text { supine } \\
\text { sitting }\end{array}$ & $\begin{array}{l}103.4 \\
111.8\end{array}$ & $\begin{array}{r}(5 \cdot 0) \\
(11 \cdot 6)\end{array}$ & $\begin{array}{l}69 \cdot 1 \\
73 \cdot 6\end{array}$ & $\begin{array}{l}(4 \cdot 9) \\
(9 \cdot 2)\end{array}$ & $\begin{array}{l}93 \cdot 3 \\
94 \cdot 1\end{array}$ & $\begin{array}{r}(8 \cdot 9) \\
(10 \cdot 2)\end{array}$ & $\begin{array}{l}47 \cdot 7 \\
50 \cdot 9\end{array}$ & $\begin{array}{l}(8 \cdot 6) \\
(9 \cdot 9)\end{array}$ & $\begin{array}{l}2.02 \\
1.90\end{array}$ & $\left.\begin{array}{l}(0.39) \\
(0.28)\end{array}\right\} N S$ \\
\hline No treatment & (9) & $\begin{array}{l}\text { supine } \\
\text { sitting }\end{array}$ & $\begin{array}{r}134 \cdot 2 \\
91.8\end{array}$ & $\begin{array}{l}(26 \cdot 0) \\
(19 \cdot 5)\end{array}$ & $\begin{array}{l}78 \cdot 4 \\
56 \cdot 9\end{array}$ & $\begin{array}{l}(11 \cdot 7) \\
(16 \cdot 3)\end{array}$ & $\begin{array}{r}107.9 \\
73.9\end{array}$ & $\begin{array}{l}(20 \cdot 8) \\
(14 \cdot 6)\end{array}$ & $\begin{array}{l}43 \cdot 3 \\
42 \cdot 3\end{array}$ & $\begin{array}{l}(6 \cdot 8) \\
(5 \cdot 4)\end{array}$ & $\begin{array}{l}2.59 \\
1.81\end{array}$ & $\left.\begin{array}{l}(0.79) \\
(0.62)\end{array}\right\} \star$ \\
\hline F L & (6) & $\begin{array}{l}\text { supine } \\
\text { sitting }\end{array}$ & $\begin{array}{l}139 \cdot 0 \\
110.7\end{array}$ & $\begin{array}{l}(27.5) \\
(35.9)\end{array}$ & $\begin{array}{l}83 \cdot 0 \\
67 \cdot 7\end{array}$ & $\begin{array}{l}(9 \cdot 6) \\
(17 \cdot 9)\end{array}$ & $\begin{array}{r}108.6 \\
88.4\end{array}$ & $\begin{array}{l}(16 \cdot 5) \\
(26 \cdot 4)\end{array}$ & $\begin{array}{l}44 \cdot 3 \\
44 \cdot 3\end{array}$ & $\begin{array}{l}(4 \cdot 6) \\
(3 \cdot 4)\end{array}$ & $\begin{array}{l}2.47 \\
1.98\end{array}$ & $\left.\begin{array}{l}(0.45) \\
(0.54)\end{array}\right\} \star$ \\
\hline DOPS & (7) & $\begin{array}{l}\text { supine } \\
\text { sitting }\end{array}$ & $\begin{array}{l}144.0 \\
118.9\end{array}$ & $\begin{array}{l}(24 \cdot 2) \\
(22 \cdot 1)\end{array}$ & $\begin{array}{l}87.4 \\
74.9\end{array}$ & $\begin{array}{l}(13 \cdot 1) \\
(11 \cdot 3)\end{array}$ & $\begin{array}{r}118.2 \\
97.9\end{array}$ & $\begin{array}{l}(18 \cdot 1) \\
(13 \cdot 5)\end{array}$ & $\begin{array}{l}41.5 \\
45.0\end{array}$ & $\begin{array}{l}(5 \cdot 4) \\
(8 \cdot 7)\end{array}$ & $\begin{array}{l}2.94 \\
2.28\end{array}$ & $\left.\begin{array}{l}(0.80) \\
(0.67)\end{array}\right\} \star$ \\
\hline
\end{tabular}

Keys-F L: fludrocortisone; BP: blood pressure; rCBF: regional cerebral blood flow; DOPS: L-threo-3,4-dihydroxyphenylserine; SD: standard deviation; ISI: initial slope index.

*: paired $t$ test, $\mathrm{p}<0.05,2$-tailed.

ns: not significant.

Table 2 Changes in blood pressure and regional cerebral blood flow on sitting up from supine position

\begin{tabular}{|c|c|c|c|c|c|c|c|c|c|c|c|}
\hline \multirow[b]{2}{*}{ Subjects } & \multirow[b]{2}{*}{ (Number) } & \multicolumn{2}{|c|}{$\begin{array}{l}\text { Changes in } \\
\text { systolic BP }\end{array}$} & \multicolumn{2}{|c|}{$\begin{array}{l}\text { Changes in diastolic } \\
B P\end{array}$} & \multicolumn{2}{|c|}{$\begin{array}{l}\text { Changes in mean } \\
B P\end{array}$} & \multicolumn{2}{|c|}{$\begin{array}{l}\text { Changes in } r C B F \\
\text { (ISI) }\end{array}$} & \multicolumn{2}{|c|}{$\begin{array}{l}\text { Changes in } \\
\text { mean } B P / r C B F\end{array}$} \\
\hline & & mean & $(S D)$ & mean & $(S D)$ & mean & $(S D)$ & mean & $(S D)$ & mean & $(S D)$ \\
\hline $\begin{array}{l}\text { Normal controls } \\
\text { Patients }\end{array}$ & (9) & $-3 \cdot 1$ & $(6 \cdot 2)$ & $4 \cdot 4$ & $(7 \cdot 7)$ & 0.8 & $(5 \cdot 4)$ & $3 \cdot 2$ & $(5 \cdot 0)\}$ & $-0 \cdot 12$ & $(0 \cdot 26)$ \\
\hline $\begin{array}{l}\text { No treatment } \\
\text { F L } \\
\text { DOPS }\end{array}$ & $\begin{array}{l}(9) \\
(6) \\
(7)\end{array}$ & $\begin{array}{l}-42 \cdot 4 \\
-28 \cdot 3 \\
-25 \cdot 1\end{array}$ & $\begin{array}{l}(28 \cdot 4) \\
(20 \cdot 6) \\
(12 \cdot 9)\end{array}$ & $\begin{array}{l}-21 \cdot 6 \\
-15 \cdot 3 \\
-12 \cdot 6\end{array}$ & $\left.\begin{array}{r}(17.9) \\
(12.7) \\
(9.9)\end{array}\right\} \star$ & $\begin{array}{l}-34 \cdot 1 \\
-20 \cdot 1 \\
-20 \cdot 3\end{array}$ & $\left.\begin{array}{l}(20 \cdot 9) \\
(14 \cdot 0) \\
(11 \cdot 7)\end{array}\right\} \star$ & $\begin{array}{r}-1 \cdot 0 \\
0 \cdot 0 \\
3 \cdot 6\end{array}$ & $\left.\begin{array}{l}(2 \cdot 9) \\
(2 \cdot 9) \\
(4 \cdot 8)\end{array}\right\}$ & $\begin{array}{l}-0.77 \\
-0.49 \\
-0.66\end{array}$ & $\left.\begin{array}{l}(0.49) \\
(0.39) \\
(0.25)\end{array}\right\}$ * \\
\hline
\end{tabular}

Key-F L: fludrocortisone; BP: blood pressure; rCBF: regional cerebral blood flow; DOPS: L-threo-3,4-dihydroxyphenylserine; ISI: initial slope index; SD: standard deviation.

$\star$ : paired $t$ test, $\mathrm{p}<0.05,2$-tailed.

$\star \star$ : Wilcoxon rank sum test, $p=0.050,2$-tailed

$\star \star \star$ : Wilcoxon matched-pairs signed rank test, $p=0.047,2$-tailed.

of these differences were statistically significant ( $t$ test and Wilcoxon rank sum test) (table 1).

On sitting up, the mean arterial blood pressure remained unaltered and the $\mathrm{rCBF}$ increased slightly in the normal controls (table 2). In contrast, in untreated patients with the Shy-Drager syndrome the mean rCBF fell. The fall was not statistically significant as the rCBF at sitting and supine positions were
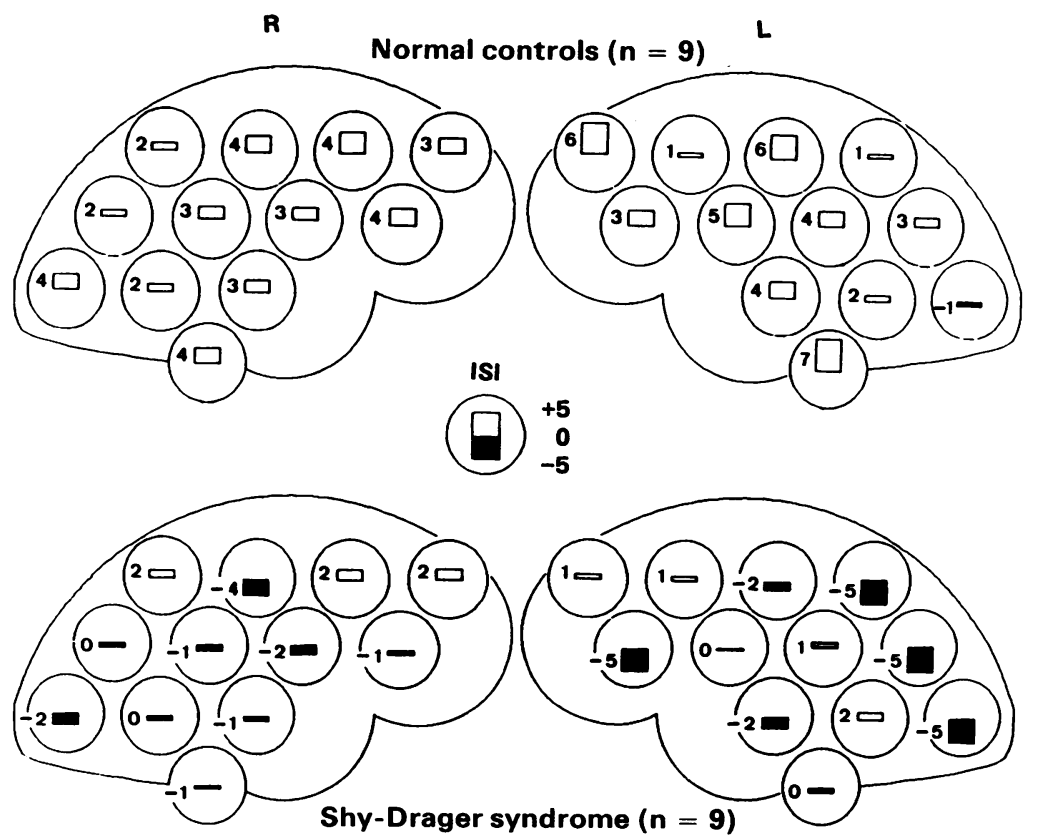

Figure 1 Changes in the regional cerebral blood flow ( $r C B F$ ), indicated in initial slope index (ISI), on sitting up from a supine position in the normal controls (top) and in Shy-Drager syndrome (bottom), in the right $(R)$ and left $(L)$ hemispheres. Open and closed squares indicate increase and decrease in $r C B F$ respectively. The data were indicated as whole numbers counting fractions of 0.5 and over and disregarding the rest. compared. But the statistical comparison between the patients and normal controls showed a tendency for the rCBF to fall in the patients ( $\mathrm{p}=0.050$ Wilcoxon rank sum test) (table 2).

Administration of fludrocortisone and DOPS reduced the fall in the mean arterial blood pressure and diastolic blood pressure respectively ( $\mathrm{p}<0.05$, paired $t$ test) in cases of the Shy-Drager syndrome (table 2). DOPS reduced the fall of the $\mathrm{rCBF}$ on sitting up ( $p$ $=0.047$, Wilcoxon matched-pairs signed rank test). The fludrocortisone tended to reduce the fall of $\mathrm{rCBF}$, but the effect was not statistically significant. One of the seven patients who were given fludrocortisone $0.2 \mathrm{mg}$ daily developed congestive heart failure due to retention of fluid. In this case the rCBF after fludrocortisone could not be examined.

The mean arterial blood pressure/rCBF ratio fell significantly on sitting up in the cases of Shy-Drager syndrome both before and during the treatment ( $\mathrm{p}<0.05$, paired $t$ test), while it did not change in the controls (table 1). The fall of the ratio on sitting up was reduced significantly when the patients were treated with fludrocortisone $(\mathrm{p}<0.05$, paired $t$ test) (table 2).

In terms of the distribution of the rCBF in the cerebral hemisphere, the cases of the ShyDrager syndrome showed a decrease of rCBF by more than 0.5 in initial slope index on sitting up in 13 out of 24 regions examined, while the normal controls showed only minimal decrease in one region (fig 1 ). In Shy-Drager syndrome, a prominent fall was observed in the occipital regions, particularly on the left, in contrast to the upper frontal regions of both sides where no decrease of 
Table 3 Comparison of degrees of improvement by two drugs

\begin{tabular}{|c|c|c|c|c|c|c|}
\hline \multirow[b]{3}{*}{ Medication } & \multirow[b]{3}{*}{ (Number) } & \multicolumn{3}{|c|}{ Reduced blood pressure fall\# } & \multirow{2}{*}{$\begin{array}{l}\text { Reduced\# } \\
\text { rCBF fall } \\
\text { (ISI) }\end{array}$} & \multirow{2}{*}{$\begin{array}{l}\text { Reduced } \\
\text { change of } \\
\text { mean } B P / r C B F\end{array}$} \\
\hline & & Systolic BP & Diastolic BP & Mean BP & & \\
\hline & & $\underset{[\text { conf int }]}{\text { mean }}(S D)$ & $\operatorname{mean}_{[\text {conf int }]}(S D)$ & $\operatorname{mean}_{[\text {conf int }]}(S D)$ & $\operatorname{mean}_{[\text {conf int }]}(S D)$ & $\begin{array}{l}\text { mean } \\
{[\text { conf int }]}\end{array}$ \\
\hline F L & (6) & $\begin{array}{l}21 \cdot 3 \quad(34 \cdot 3) \\
{[-14 \cdot 7 / 57 \cdot 3]}\end{array}$ & $\begin{array}{l}10 \cdot 7 \quad(26 \cdot 2) \\
{[-16 \cdot 9 / 38 \cdot 2]}\end{array}$ & $\begin{array}{l}21 \cdot 8 \\
{[4 \cdot 2 / 39 \cdot 4]}\end{array}$ & $\begin{array}{l}1 \cdot 2 \\
{[-2 \cdot 7 / 5 \cdot 2]}\end{array}$ & $\begin{array}{l}0.42 \\
{[0.14 / 0.70]}\end{array}$ \\
\hline DOPS & (7) & $\begin{array}{l}21 \cdot 7 \quad(37 \cdot 7) \\
{[-13 \cdot 1 / 56 \cdot 5]}\end{array}$ & $\begin{array}{l}13.1 \\
{[0.7 / 25 \cdot 6]}\end{array}$ & $\begin{array}{l}19 \cdot 6 \quad(26 \cdot 1) \\
{[-4 \cdot 5 / 43 \cdot 7]}\end{array}$ & $\begin{array}{l}4 \cdot 6 \quad(5 \cdot 5) \\
{[-0 \cdot 5 / 9 \cdot 7]}\end{array}$ & $\begin{array}{l}0.26 \quad(0.46) \\
{[-0.17 / 0.69]}\end{array}$ \\
\hline
\end{tabular}

Key-F L: fludrocortisone; BP: blood pressure; rCBF: regional cerebral blood flow; DOPS: L-threo-3,4-dihydroxyphenylserine; ISI: initial slope index; SD: standard deviation.

conf int: $95 \%$ confidence interval [lower limit/upper limit].

\#: reduced BP (rCBF) fall = change in BP (rCBF) on sitting up during treatment-change in BP (rCBF) on sitting up before treatment.
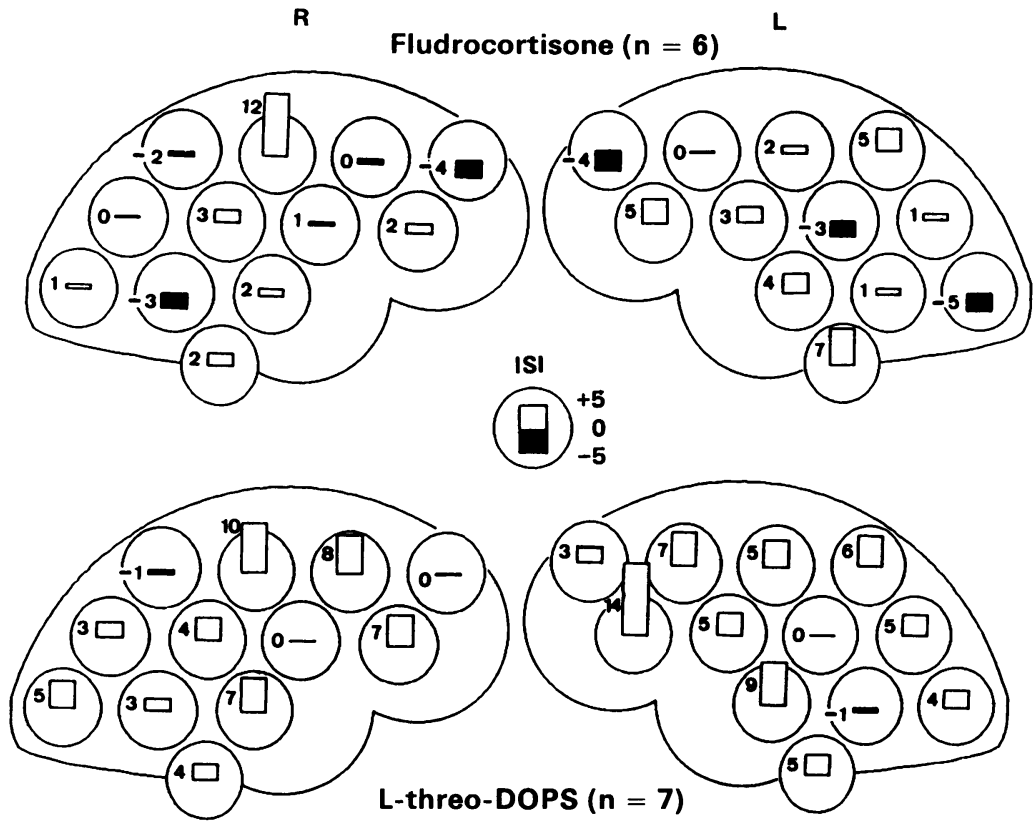

Figure 2 Reduction of the decrease of $r C B F$ in patients on sitting up and taking fludrocortisone (top) and DOPS (bottom). The data were calculated in the same manner as those in table 3. The open and closed squares indicate reduction and amplification of the decrease of $r C B F$ respectively on treatment. All data were indicated as whole numbers. on average on sitting up. The tendency of the rCBF to fall was observed compared to the normal controls, though the difference between the supine and sitting positions of the patients was not statistically significant.

Whether the autoregulation of cerebral circulation at low blood pressure is impaired, ${ }^{8}$ partially impaired ${ }^{9}$ or preserved ${ }^{1011}$ in cases of the Shy-Drager syndrome has been controversial. The results of this study have much in common with those of Brooks et al, ${ }^{11}$ who showed preservation of the CBF and a reduction of the middle cerebral artery velocity on tilting up, indicating an intact cerebral autoregulation and reactive vasodilatation respectively. The mean arterial blood pressure/ rCBF ratio reflects the vascular resistance in the carotid and cerebral circulation. ${ }^{12}$ The fall of the ratio on sitting up in our cases suggested decreased vascular resistance due to vasodilatation, an effect of the cerebral autoregulation. ${ }^{11} 13$

In the cases of Shy-Drager syndrome in this study, the CBF showed a tendency to decrease on sitting up compared with normal controls, along with a fall of mean arterial blood pressure by $32 \%$ or down to $74 \mathrm{~mm} \mathrm{Hg}$; none of the cases that showed decrease of rCBF had systolic pressure less than $70 \mathrm{~mm}$ $\mathrm{Hg}$ at sitting position. This degree of fall in the blood pressure may be within the limit of normal cerebral autoregulation in baboons ${ }^{14}$ and humans. ${ }^{1015}$ Although mild in degree, this fall of CBF may still point to a certain degree of impairment of the cerebral autoregulation.

One of the causes that obscured the fall of the total CBF on sitting up was uneven distribution of the change in the rCBF on the cerebral hemisphere. The rCBF was relatively preserved in the frontal regions. Depresseux ${ }^{9}$ noted the same phenomenon in a case of ShyDrager syndrome and attributed it to anxiety. This explanation seems quite possible, as mental activity enhances the rCBF in the prefrontal region. ${ }^{16}$ Despite the marked fall in rCBF in the occipital region, no visual impairment or any symptoms of vertebrobasilar insufficiency was noticed by the patients during the investigation. However, seven out of nine patients had experienced blurring or darkening of the vision as they stood up. These common visual symptoms in cases of ShyDrager syndrome may have some relevance to the fall in $\mathrm{rCBF}$ in the occipital region. 
Fludrocortisone has been used widely in the treatment of orthostatic hypotension ${ }^{17}$ as it elevates the blood pressure by increasing the plasma volume. In this study, it diminished the fall of blood pressure significantly on sitting up. It also tended to reduce the fall of $\mathrm{rCBF}$, though the reduction was not statistically significant. Fludrocortisone may cause various side effects and some of them can be severe. ${ }^{17}$ In the course of fludrocortisone treatment, one of our patients developed congestive heart failure.

The DOPS raised the blood pressure ${ }^{18}$ and increased the CBF in animals. ${ }^{19}$ On the other hand, patients treated with DOPS for Parkinson's disease showed changes neither in the blood pressure nor in the $\mathrm{rCBF}^{20}$ The same was the case in the present series. However, DOPS did reduce the fall of the diastolic blood pressure and of the rCBF significantly on sitting up.

The DOPS is converted into norepinephrine by aromatic L-amino acid decarboxylase. ${ }^{21}$ Since DOPS did not raise the blood pressure in normal subjects, denervation supersensitivity to norepinephrine was suggested as an explanation for the pressor response in orthostatic hypotension. ${ }^{3}$ In a case of Shy-Drager syndrome Kachi et $a l^{4}$ demonstrated a paucity of muscle sympathetic activity and its increase after administration of DOPS. They suggested that DOPS activates the sympathetic outflow at a site proximal to the sympathetic ganglia.

The systemic pressor action of DOPS certainly contributes to the preservation of the CBF at sitting position in Shy-Drager syndrome. Whether DOPS has any effect on the cerebral circulation other than that through the systemic pressor action deserves further discussion. In humans a direct infusion of catecholamines into the carotid artery did not change the $\mathrm{CBF}^{22}$ while in animals intravenous infusion of catecholamine increased, ${ }^{23}$ decreased $^{24}$ or left the CBF unaltered..$^{25}$

Norepinephrine is known to increase the $\mathrm{CBF}$ when it penetrates the blood-brain barrier (BBB). ${ }^{24}$ Since a small proportion of DOPS penetrates the $\mathrm{BBB},{ }^{212627}$ it will exert the same action after conversion into the norepinephrine in the cerebral parenchyma. We thus consider the local action of DOPS in the brain along with the systemic pressor action to explain its effect.

The untoward effects of DOPS are relatively infrequent and are not very severe. ${ }^{28}$ Our patients experienced none. Because of its effect on blood pressure and rCBF comparable to that of fludrocortisone as well as relatively infrequent and less severe sideeffects, DOPS may well be an alternative choice to fludrocortisone in the treatment of Shy-Drager syndrome.

The L-threo-3,4-dihydroxyphenylserine was supplied by Sumitomo Pharmaceuticals, Osaka, Japan. We are grateful to Dr W G P Mair who kindly corrected the English.
1 Shy GM, Drager GA. A neurogenic syndrome associated with orthostatic hypotension. A clinical-pathologic study. Arch Neurol 1960;2:511-27.

2 Chobanian AV, Volicer L, Tifft CP, Gavras H, Liang C-S, Faxon D. Mineralocorticoid-induced hypertension in patients with orthostatic hypotension. New Engl J Med 1979;301:68-73.

3 Suzuki T, Higa S, Sakoda S, et al. Pharmacokinetic studies of oral L-threo-3,4-dihydroxyphenylserine in normal subjects and patients with familial amyloid polyneuropathy. Eur J Clin Pharmacol 1982;23:463-8.

4 Kachi T, Iwase S, Mano T, Saito M, Kunimoto M, Sobue I. Effect of L-threo-3,4-dihydroxyphenylserine on muscle sympathetic nerve activities in Shy-Drager syndrome. Neurology 1988;38:1091-4.

5 Risberg J, Ali Z, Wilson EM, Wills EL, Halsey JH Jr. Regional cerebral blood flow by $133 \mathrm{Xe}$ inhalation. Stroke 1975;6:142-8.

6 Jablonski T, Prohovnik I, Risberg J, Stahl KE, Maximilian VA, Sabsay EV. Fourier analysis of 133-Xe inhalation curves. Accuracy and sensitivity. Acta Neurol Scand 1979;60(suppl 72):216-7.

7 Nelson RJ, Lovick AHJ, Pickard JD, Brice J, Saunders D, Horsey PJ. Changes in the cerebral blood flow during anaesthesia and surgery in the sitting position. $J$ Neurol Neurosurg Psychiatry 1987;50:971-5.

8 Meyer JS, Shimazu K, Fukuuchi Y, et al. Cerebral dysautoregulation in central neurogenic orthostatic hypotension (Shy-Drager syndrome). Neurology (Minneap) 1973;23:262-73.

9 Depresseux JC, Rousseau JJ, Franck G. The autoregulation of cerebral blood flow, the cerebrovascular reactivity and of cerebral blood flow, the cerebrovascular reactivity and their interaction in

10 Thomas DJ, Bannister R. Preservation of autoregulation of cerebral blood flow in autonomic failure. $J$ Neurol $S c i$ 1980;44:205-12.

11 Brooks DJ, Redmond S, Mathias CJ, Bannister R, Symon L. The effect of orthostatic hypotension on cerebral blood flow and middle cerebral artery velocity in autonomic failure, with observations on the action of ephedrine. Neurol Neurosurg Psychiatry 1989;52:962-6.

12 Schieve JF, Wilson WP. The changes in cerebral vascular resistance of man in experimental alkalosis and acidosis. $J$ Clin Invest 1953;32:33-8.

13 Keaney NP, Pickerodt VW, McDowall DG, Coroneos NJ Turner JM, Shah ZP. Cerebral circulatory and metabolic effects of hypotension produced by deep halothane anaeseffects of hypotension produced by deep halothane anaes-
thesia. J Neurol Neurosurg Psychiatry 1973;36:898-905.

14 Fitch W, MacKenzie ET, Harper AM. Effects of decreasing arterial blood pressure on cerebral blood flow in the baboon. Influence of the sympathetic nervous system. Circulation Research 1975;37:550-7.

15 Madsen JB, Cold GE, Hansen ES, Bardrum B, KruseLarsen C. Cerebral blood flow and metabolism during isoflurane-induced hypotension in patients subjected to surgery for cerebral aneurysms. Br J Anaesthesia 1987; 59:1204-7.

16 Roland PE, Eriksson L, Stone-Elander S, Widen L. Does mental activity change the oxidative metabolism of the brain? J Neurosci 1987;7:2373-89.

17 Schatz IJ. Current management concepts in orthostatic hypotension. Arch Intern Med 1980;140:1152-4.

18 Araki H, Tanaka C, Fujisawa H, Nishimura M, Ohmura I. Pressor effect of L-threo-3,4-dihydroxyphenylserine in rats. J Pharm Pharmacol 1981;33:772-7.

19 Sato E, Irie T, Katsube J. Effect of L-threo-3,4-dihydroxyphenylserine (L-DOPS), an immediate precursor of norepinephrine, on the cerebral blood flow in rats. Japan $J$ Pharmacol 1987;43:91-3.

20 Ujike H, Yamamoto $M$. Effect of L-threo-3,4-dihydroxyphenylserine on regional cerebral blood flow in patients with Parkinson's disease. J Neurol Sci 1988;83:75-80.

21 Creveling CR, Daly J, Tokuyama T, Witkop B. The combined use of alpha-methyltyrosine and threodihydroxyphenylserine. Selective reduction of dopamine levels in the central nervous system. Biochem Pharmacol 1968;17:65-70.

22 Olesen J. Beta-adrenergic effects on cerebral circulation. Cephalalgia 1986;6(supp 5):41-6.

23 Dahlgren N, Rosén I, Sakabe T, Siesjö BK. Cerebral function, metabolic and circulatory effects of intravenous function, metabolic and circulatory effects of intravenous

24 Edvinsson L, Lacombe P, Owman CH, Reynier-Rebuffel AM, Seylaz J. Quantitative changes in regional cerebral blood flow of rats induced by alpha- and beta-adrenergic stimulants. Acta Physiol Scand 1979;107:289-96.

25 Tuor UI, Edvinsson L, McCulloch J. Catecholamines and the relationship between cerebral blood flow and glucose use. Am J Physiol 1986;251:H824-33.

26 Ishikawa Y, Kato Y, Murakami Y, Inoue T, Koshiyama H, Imura $H$. Effect of $L$-threo-3,4-dihydroxyphenylserine (L-DOPS) on catecholamine levels in plasma and cerebrospinal fluid (CSF) in anesthetized rats. Proc Soc Exp Biol Med 1987;184:197-200.

27 Kato T, Katsuyama M, Karai N, Nakamura M, Katsube J. Studies on the central action of L-threo-3,4-dihydroxyphenyl-serine (L-threo-DOPS) in FLA-63-treated mice. Pharmacol Biochem Behavior 1987;26:407-11.

28 Narabayashi H, Kondo T, Yokochi F, Nagatsu T. Clinical effects of $\mathrm{L}$-threo-3,4-dihydroxyphenylserine in cases of parkinsonism and pure akinesia. Adv Neurol 1986;45: 593-602. 